\title{
Professionalism: Secondary Goals
}

Robert A. Raschke, MD

\author{
Banner Good Samaritan Medical Center \\ Phoenix, AZ
}

Please recall my lengthy disclaimer from Part 1 of this series.

In part two, we reviewed the Oath of Maimonides. We considered our profession as a sacred vocation. We defined professionalism: A good doctor can be trusted to always place his/her individual patient's best interest first, with ability, good judgment, and a caring attitude. We determined that we should be willing to make sacrifices in our commitment to our primary goal (as critical care physicians) - getting our patients and their families through their illness with as little disability and suffering as possible.

Now, my second disclaimer - I am going to express my opinions from atop my Ivory Tower - as I am not in private practice, and protected a bit from the harsh reality of the business world. I am going to express my possibly somewhat naive perspective on secondary goals related to our profession. These are not necessarily bad, but they may distract from our primary goal. I personally feel that I have to de-prioritize these goals in order to do what's best for my patients.

It is not your primary goal to run your business. I'm employed in a teaching hospital - so I can speak to this issue without having to "pay the overhead". However this was a personal choice I made early in my career, at a time when it was an unpopular and poorly-paid career path. I was able to afford it because my wife and I kept modest personal finances. The small home we raised our children in for 20 years cost less than twice my starting salary of $\$ 65,000$. We have been blessed by not having to worry much about money along the way.

The good salary we make as doctors ought to be used to achieve financial security in a modest lifestyle, so that we are less vulnerable to financial incentives. Remember, we did NOT go into medicine for the money. l've observed that some of my colleagues who spend a lot of money in their personal lives get caught-up in business practices that are not the best for their patients. I've also observed that some of the highest-earning physicians are most likely to suffer financial anxiety or even personal bankruptcy. Separate physician and business duties as much as possible. Don't hang out with or take gifts from medical salespeople that you would be at-all ashamed to tell your patients about. If you find your actions as a doctor are being unduly influenced by financial incentives, consider whether you can simplify your personal finances.

It is not your primary goal to have your patients or colleagues like you, as long as you are acting with good judgment and good attitude, in the 
patient's best interest. One of my partners recently had a very frank discussion with a patient who was strongly suspected of Munchausen's disease. Her selfdestructive behavior had resulted in numerous ICU admissions and over 20 unnecessary endotracheal intubations. It was crucial to the care of this patient that this diagnosis was confronted, to avoid other unnecessary and dangerous interventions, and so that the underlying psychiatric disease could be treated. But this confrontation prompted an angry response. The patient filed an official complaint. This complaint came at a very bad time for my partner, and actually threatened costing him his job - although thankfully this did not come to pass. I hope he is able to do the right thing again next time, but it can be hard in a system where incentives for universal patient satisfaction are strong.

Another of my partners recently expressed exasperation with the more common difficulty of properly communicating poor prognosis to overly-optimistic family members who are praying for a miracle. We agreed that we have an obligation to express the truth - withholding poor prognostic information is essentially a lie of omission. Sometimes family members misinterpret this as a pessimistic attitude rather than plain old-fashioned honesty, no matter how much compassion we bring to the topic.

I have injured my friendship and working relationship with several of my colleagues over the years because of disagreements over what was best for the patient. Conversely, some of my most shameful actions as a doctor were committed in an attempt "smooth things over" with colleagues that appeared to be trying to achieve the impossible, usually in relation to what I perceived to be futile care.

Several years ago, I was called to the bone marrow transplant unit to intubate a young woman with recurrent acute leukemia. She had previously failed two allogeneic bone marrow transplants, and had just failed an investigational chemotherapy protocol. She was in blast crisis, and rapidly developing multisystem organ failure. Worst of all, she had grade IV graft-vs-host disease and suffered florid gastrointestinal symptoms and was covered in skin lesions. She was non-communicative due to multifactorial delirium. Her family trusted the transplant hematologist, having known him for years, and they believed him when he told them that he could still save her.

The transplant hematologist and I had had many disagreements in the past in situations in which I felt that patients and their families had been subjected to unnecessary suffering in futile situations, but up to this point, we had always been able to find at least an uneasy alliance. This time though, I flat out refused perform the requested intubation, and instead strongly recommended comfort care. I explained by rational to the patient's family, who reacted with anger. The transplant hematologist consulted a critical care physician from another group who came and inbutated the patient. The patient died several days later, during infusion of stem cells as part of a third transplant attempt. 
This conflict damaged the working relationship between our groups, and hurt everyone's job satisfaction, because we all enjoyed supporting the good work done in our bone marrow unit. It also hurt our group's billings. But as best I can tell, my partners understood and supported my decision.

It is not your primary goal to avoid a lawsuit. It is an incredible blessing not to get sued in the course of your career. Besides the obvious drawbacks, the stress of a lawsuit can seriously degrade your capacity to concentrate on taking care of patients, and even lead to physical illness. A lawsuit may even be career-ending - several very good clinicians that I know have made drastic career changes as a result of lawsuits. One perinatologist became an acupuncturist after a lawsuit involving an unpredictable complication of a blood transfusion. Others dropped out of critical care to practice office medicine or take administrative jobs.

But our primary goal takes precedence over medical-legal concerns. The practice of defensive medicine often leads patients to suffer complications of medically unnecessary procedures. Honesty in disclosure of errors is an ethical facet of our profession that often conflicts with the desire to avoid lawsuits. I once disclosed a major error in anticoagulation therapy that led to potentially disfiguring complications of cosmetic facial surgery to a young woman and her husband this motivated them to send a letter to the CEO of our hospital at the time (the guy who signs my paycheck). Another time, I disclosed to a family that a patient's previously unexplained in-hospital mortality had been determined to be caused by a transfusion-related West Nile Virus infection. I had exerted a major effort to make this obscure post-mortem diagnosis, the discovery and disclosure of which led to a request for records from a law-firm retained by the family.

I very much appreciate the help of the lawyers and paralegal staff of our risk management department, but I purposely avoid asking them for advice in situations when I already know the right thing to do for the patient.

\section{It is not your primary goal to achieve external measures of "quality" or} utilization. Recently, the idea of physician "report cards" has been popularly embraced, and many employed physicians now have financial incentives based on surrogate measures of quality-of-care. Unfortunately many of the pooled outcomes used to define quality are difficult to interpret in the care of an individual patient. Recall the story of the liver transplant patient who received prolonged futile care (related in part 2 of this series). Note that the initial, poorlyfocused care of this patient benefitted the 12-month mortality statistic for the transplant program, while appropriate comfort-focused care of the patient worsened the ICU mortality statistic. This example shows how statistics that sound like very valid measures of quality can be very misleading.

Other surrogate markers of "quality" are initially supported by what seems like high-level experimental evidence, but are later found to lack benefit, or in some 
cases even cause harm. Recent examples in our specialty include early goaldirected therapy for severe sepsis, tight glucose control and the use of drotrecogan-alpha $\left(\right.$ Xigris $\left.^{\circledR}\right)$.

Even valid surrogate measures of quality are likely to greatly oversimplify what it means to be a good doctor, focusing excessively on a few particular elements of care, and distracting from aspects that might be more important to an individual patient.

I resist being incentivized to achieve any measure that may conflict with my primary goal, but also think we ought to analyze our "quality data" with open and self-critical minds. I do my best to use it to learn to how to make myself a better doctor, rather than concentrating solely on making my statistics improve. I think it is best to simply do the best job you can for each individual patient, prioritizing the things that are most important to that person, and let specific individual data points that others use to define quality fall where they may.

I don't like being on committees, but I force myself to be involved in the process by which quality measures are chosen. I bring skepticism to the meetings, even in regards to practices that are currently "evidence-based" - because history proves that many of these will eventually be found to be erroneous. I try to champion quality improvement processes that make the most sense, such as hand-washing, and getting unnecessary invasive hardware (such as unneeded Foley catheters, and IV lines) out as soon as possible.

Unfortunately, the un-professional behavior of a few among us has damaged the trust that most people have for their doctors, providing a rationale for monitoring and incentivizing our behavior. But real professionals don't need to be financially incentivized to do what's right. It is my opinion that the people who most want to incentivize us (politicians and administrators) do not have the wisdom to pick the right actions to incentivize, and may not always have the individual patient's best interests at heart.

Capacity: You have to be cognitively, psychologically and physically healthy to do your best work as a doctor. I studied medicine pretty hard during my training, but I am fundamentally intellectually (and all-around) lazy. Once I went into practice, I found I had trouble keeping current with medical literature, no longer having to worry about board exams. Trying to force myself to read worked about as well as most diets. Eventually the problem was solved when I started a monthly Critical Care journal club with our fellows. This forced me to review the current literature each month, and actually read the articles carefully. We each have our own ways to stay current, but having a teaching job is a big advantage. It justifies study as a job duty, and protects some time for you to work on it.

Happiness in your personal life will reflect on your ability to survive stress and maintain the right attitude at work. My wife Carolyn has been a wonderful 
blessing to me in this regard, and has helped me be a better doctor. Back in the days before we took night call, whenever my pager went off at night, it woke us both up. I would call in and try to figure out over the phone whether the patient was sick enough to warrant getting out of bed and driving in to the hospital in the middle of the night. It was pretty obvious to Carolyn that my ability to make good decisions when awoken from delta waves at 3 AM was questionable at best. She suggested that I should just go in and see every ICU admit no matter how things sounded over the phone. "You don't do anything but toss and turn in bed anyway worrying that you should have gone in".

This was a little extreme at the time for a teaching program, because we already had interns and residents in house all night. But it was endorsed by my wife, and it helped improve our patient care. The system was adopted by our entire group and practiced until we switched to 24-hour in-house coverage. My happy marriage and supportive home life are an important counterbalance to the disappointments I often face in the ICU.

Exercise regularly - you ought to be able to get some exercise even during your busiest work weeks. Whether you like running, yoga, weight-lifting or playing with your dog, your physical capacity and ability to concentrate will benefit from regular physical activity outside the hospital. I try to do some form of exercise at least twice a week, no matter how late I get home, even if it's only for ten minutes.

Don't take a job that will exceed your capacity to provide good care. I have seen hospitalists with a work list exceeding 50 patients for weekend rounds. No matter how efficient you are, no one can reliably do a good job with that magnitude of work load.

Feel free to comment if you disagree with part or all of the above. They are just the personal opinions of a confessed ex-altar-boy and boy scout!

END OF PART THREE (next: part 4: "Attitude") 